\title{
Impact of the use and efficacy of long lasting insecticidal net on malaria infection during the first trimester of pregnancy - a pre-conceptional cohort study in southern Benin
}

Cornélia Hounkonnou ${ }^{1,2^{*}}$ (D), Armel Djènontin ${ }^{3,4}$, Seun Egbinola ${ }^{5}$, Parfait Houngbegnon ${ }^{2}$, Aziz Bouraima ${ }^{4}$, Christophe Soares $^{4}$, Nadine Fievet ${ }^{1}$, Manfred Accrombessi ${ }^{1,2}$, Emmanuel Yovo $^{2}$, Valérie Briand ${ }^{1}$ and Gilles Cottrell ${ }^{1 *}$

\begin{abstract}
Background: Malaria in pregnancy is prevalent in Sub-Saharan Africa. The first trimester of pregnancy is a critical period and the best preventive measure is Long Lasting Insecticidal Nets (LLIN). Unfortunately, few studies have been conducted which focuses on the usage and efficacy of LLIN on malaria prevention during the first trimester.

Methods: We assessed the use and effectiveness of LLIN in early pregnancy in Benin and its impact on malaria infection risk. We followed-up a cohort of 240 pregnant women from pre-conception to the end of the first trimester of pregnancy in Southern Benin. Parasitological, maternal and LLIN data were actively collected before, at the beginning and end of the first trimester of pregnancy. A Cox regression model was used to determine the relationship between the time to onset of the first malaria infection and the use, physical integrity, and bio-efficacy of the LLIN, adjusted for relevant covariables.
\end{abstract}

Results: The good use, good physical integrity and biological efficacy of LLIN were associated with a decreased risk of occurrence of the first malaria infection in early pregnancy ( $\mathrm{HRa}=0.38 ;(0.18-0.80) ; p<0.001 ; \mathrm{HRa}=0.59 ;(0.29-1.19) ; p$ $<0.07 ; \mathrm{HRa}=0.97 ;(0.94-1.00) ; p<0.04$ respectively), after adjustment for other covariates. Primi/secundigravidity and malaria infection before pregnancy were associated with a risk of earlier onset of malaria infection.

Conclusion: The classically used LLIN's indicators of possession and use may not be sufficient to characterize the true protection of pregnant women in the first trimester of pregnancy. Indicators of physical integrity and bio-efficacy should be integrated with those indicators in evaluation studies.

Keywords: Gestational malaria, First trimester, Long lasting impregnated nets, Use, Physical integrity indicator, Biological efficacy indicator

\footnotetext{
*Correspondence: nellsmilia@yahoo.fr; gilles.cottrell@ird.fr

'UMR216-MERIT, French National Research Institute for Sustainable

Development (IRD), Université Paris Descartes, 75006 Paris, France

Full list of author information is available at the end of the article
}

(c) The Author(s). 2018 Open Access This article is distributed under the terms of the Creative Commons Attribution 4.0 International License (http://creativecommons.org/licenses/by/4.0/), which permits unrestricted use, distribution, and reproduction in any medium, provided you give appropriate credit to the original author(s) and the source, provide a link to the Creative Commons license, and indicate if changes were made. The Creative Commons Public Domain Dedication waiver (http://creativecommons.org/publicdomain/zero/1.0/) applies to the data made available in this article, unless otherwise stated. 


\section{Background}

Malaria in pregnancy results in an increased risk of low birth weight (LBW) [1-3], maternal anemia and perinatal mortality [1, 4]. World Health Organization (WHO) has implemented a prevention policy specific to this vulnerable population [5, 6], based on sulfadoxine-pyrimethamine (SP) intermittent preventive treatment in pregnant women (IPTp) and the use of Long Lasting Impregnated Nets (LLIN) from the onset of pregnancy. The IPTp comprises monthly intakes of a curative dose of SP during antenatal care visits from the second trimester of pregnancy for all pregnant women (whether infected or not). Numerous studies have shown the effectiveness of IPTp in improving maternal and child health outcomes [7-10]. However, IPTp is contraindicated in the first trimester of pregnancy leaving women in the first trimester unprotected by this control tool. Moreover, several studies have shown that the first trimester of pregnancy is a critical period during which malaria infection is associated with an increased risk of low birth weight and maternal anemia [11-13]. LLIN is the only preventive tool available for pregnant women during this period. However, it is known that pregnant women attend the maternity clinic mostly after the first trimester of pregnancy in sub-Saharan Africa [14]. Consequently, the first trimester of pregnancy is a period badly covered by the malaria prevention policy. There is evidence for the efficacy of LLIN in preventing malaria infection during pregnancy [15], to improve babies' birth weight [16]. No study has yet focused on the specific protection conferred by LLIN in the first trimester of pregnancy. In this work, using data from the follow-up of a pre-conceptional cohort carried out in South-Benin in 2015-1016, we evaluated the association between the indicators of use, physical integrity and bio-efficacy of LLINs used by pregnant women and malaria incidence during the first trimester of pregnancy.

\section{Methods}

\section{Study design}

EVALMOUS is a cohort study nested in the RECIPAL project, carried out in South Benin [17]. Between June 2014 and August 2017, 1214 women of childbearing age and willing to become pregnant (primary cohort) were included in a cohort follow-up. All women were screened for malaria using thick blood smear (TBS) at their inclusion and monitored monthly using a urinary pregnancy test until the identification of 411 pregnant women among them (secondary cohort). The pregnant women were then monitored monthly until delivery at the maternity clinic, where they benefited from a clinical, parasitological (by TBS), nutritional and ultrasound follow-up. Lambarene technique was used to quantify parasitaemia and the detection threshold with this method has been estimated to be 5 parasites/ $\mu \mathrm{L}$ [18]. In addition, in the event of fever or symptoms suggestive to malaria, pregnant women were screened using Rapid Diagnostic Tests (RDT) and treated with Artemisinin-based Combination Therapies (ACT) when tested positive for malaria according to the national guidelines [19].

EVALMOUS study held between 1st June 2015 and 31st October 2016 and aimed to assess the effectiveness of mosquito nets used by pregnant women and other members of their household in preventing malaria. The first 576 women from the RECIPAL primary cohort who agreed to participate were included in EVALMOUS study before their pregnancy and the first 240 of them to become pregnant were followed throughout the first trimester of pregnancy. Women were visited at three home visits: a first visit was performed before pregnancy and two visits during the first trimester of pregnancy. During these visits, a questionnaire was administered to the women in order to evaluate the indicators related to LLIN, namely: possession, use and physical integrity. At the last visit the mosquito net used by the pregnant women was taken for laboratory testing to assess their bio-efficacy and replaced by new ones provided by the study. Physical integrity and bio-efficacy of the LLINs were determined by the field workers using the standard WHO protocol [20].

\section{Variables \\ Outcome variable}

Malaria infection during the first trimester of pregnancy was defined as a positive blood smear and/or a positive RDT before 15 weeks of gestation (estimated by early ultrasound scan). Timing of malaria infection was determined based on gestational age.

\section{Independent variables}

At each visit during the study (before pregnancy and during the first trimester of pregnancy), the use of mosquito net was defined as a binary variable, "good" if LLIN was reported to be used every day of the week preceding the visit and if it was properly installed after inspection by the investigator.

The physical integrity of nets was characterized by a hole index (hi) resulting from the characterization of the holes according to WHO protocol [20]. A mosquito net with a hi between 0 and 64 was considered as in "good" condition, a hi between 65 and 642 as in an "acceptable" state and a hi greater than 643 as in a "bad" state.

Bio-efficacy of LLIN was based on both kd60 (knock-down $60 \mathrm{~min}$ ) and $24 \mathrm{~h}$-death (mortality after $24 \mathrm{~h}$ ) of female Anopheles gambiae "Kisumu strain" 2-5 days after exposure to LLIN through standard WHO cone. A LLIN was declared bio-effective when the kd60 rate induced by this LLIN is greater than or equal to $95 \%$ or when the mortality rate induced by it is greater than or equal to $80 \%$ [20]. 


\section{Statistical analysis}

First, we did a descriptive analysis of the general characteristic of the women at baseline (sociodemographic, the characteristics of the LLINs and the malaria before pregnancy).

\section{Univariable analysis}

We studied the relationship between the time to onset of the first malaria infection in the first trimester of pregnancy and each of the independent variables by a univariable Cox regression model. For each covariate, the proportional risk hypothesis was verified using the overall "p" of the Schoenfeld residue-based test. For the continuous covariates, the linearity hypothesis was verified. The comparison between the Kaplan-Meier curves of the different categories of qualitative variables was carried out by a log rank test.

\section{Multivariable analysis}

The malaria infection and the LLINs indicators were available for 190 pregnant women out of the 240. We compared the 190 pregnant women included in the multivariable analysis and the 50 excluded women according to the age (t-test), the gestational rank, the residence area and the malaria infection before pregnancy. The comparison of the age in the two groups was performed by a t-test whereas the categorical variables were compared using a Chi2 test.

A multivariable Cox regression model was used. Adjustment factors were age (in years) of the pregnant women (quantitative variable recoded in quartiles); the gestational rank (less than 3 pregnancies/more than 3 pregnancies; marital status (unmarried/married); pre-pregnancy malaria infection during the pre-pregnancy visit; ethnicity (Toffin/other); level of education (literate/illiterate); occupational status (employed/unemployed) and residential area (lake area/land area).

First, all covariates were introduced in the model and a backward step-by-step strategy was performed to eliminate non-significant cofactors. At the end of the analysis, only the cofactors associated with the variable to be explained at the $5 \% p$-value threshold were retained in the final model in addition to the LLIN indicator variables. As we considered in this study one-sided alternative hypotheses (i.e. better use, better physical integrity and better bio-efficacy would confer protection against malaria), we used one-sided $p$-values with a threshold of significance at $5 \%$.

During the study, six pregnant women had at least 2 malaria infections during the first trimester of pregnancy. In order to assess the determinants of the number of infections, we performed a multivariable Poisson regression model, regressing the same covariates (as in the Cox model) on the number of infections in the first trimester. In addition, in order to take into account the different number of measures between the women, an offset (the log of the number of visits) has been introduced in the model.

The analyses were carried out with STATA software version 13.1 (STATA Corporation, Texas).

\section{Results}

Five hundred and seventy-six pregnant women were included in the EVALMOUS study. Figure 1 shows the flow chart during follow-up of these women. We included 240 pregnant women. At the end of the eighteen months of follow-up, the proportion of drop-out, miscarriages, and refusals was $0.42 \% ; 8.33$ and $5 \%$ respectively. The bioassays were carried out in the laboratory on 324 LLINs at the end of the first trimester.

The characteristics of the pregnant women included in the study are shown in Table 1 . Among the 240 women, the prevalence of malaria infection before pregnancy was $4.41 \%$ and the proportion of infected pregnant women during the first trimester of pregnancy was $18.33 \%$. All women except one had an LLIN.

During pregnancy, all but one of the women had LLINs. Most of pregnant women (83.25\%) had used their LLIN properly during the week prior to the visits. About $60 \%$ of the LLINs inspected were in good physical condition. On the other hand barely $6 \%$ of LLINs tested in the laboratory were bio-effective. Table 2 recapitulates the characteristics of the LLIN's indicators inspected.

Table 3 shows the different proportions of malaria infection during the different visits of the first trimester of pregnancy. The median time between onset of malaria before pregnancy and the beginning of pregnancy was 7.6 months with an interquartile range of (4.9-8.5).

Figure 2 shows the probability of non-occurrence of malaria infection in pregnant women as a function of time during the first trimester of pregnancy. The incidence rate of malaria infections was 7.18 cases per 100 person-months (95\% CI: 5.36-9.62).

The group of women not included in the multivariate analysis did not differ significantly from the included pregnant women, according to the 4 variables: age, residence area, gestational rank and malaria before pregnancy (respective $p$-values $=0.48 ; 0.29 ; 0.24$ and 0.58 respectively). Based on those results, excluding the 50 women from the multivariable model does not seem to have led to a major selection bias.

The variables selected in the final multivariate model respected the proportional hazard asumption assumption according to the Schöenfeld residuals method.

Additional file 1: Table S1 and Table 4 respectively summarize the univariate Cox regression model and the final multivariate Cox model. After adjustment, the use of LLIN by pregnant women was marginally significant, whereas the physical integrity, the LLIN's quantitative 


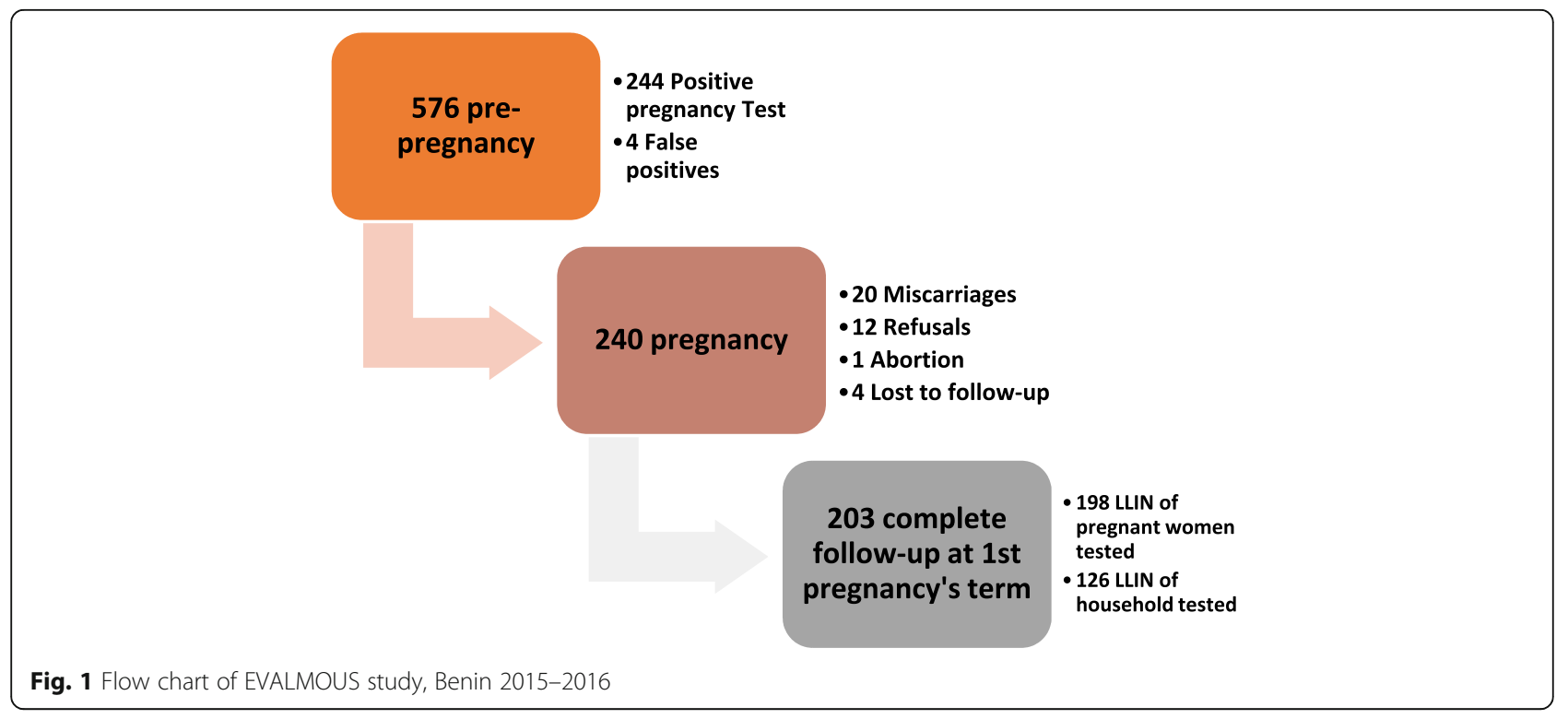

Table 1 Characteristics of pregnant women at the inclusion, Sô-Ava and Akassato, Benin 2015-2016 ( $N=240)$

\begin{tabular}{|c|c|c|}
\hline \multirow[t]{3}{*}{ Characteristics } & \multicolumn{2}{|c|}{ Pre-pregnancy } \\
\hline & Total & Mean or proportion \\
\hline & & $(95 \% \mathrm{Cl})$ \\
\hline Age (years) & 240 & $26.61 \pm 4.78$ \\
\hline Gestational rank & 240 & \\
\hline Primigravida & 22 & $9.17(5.49 ; 12.84)$ \\
\hline Secundigravida & 36 & $15.00(10.45 ; 19.55)$ \\
\hline Multigravida & 182 & $75.83(70.38 ; 81.29)$ \\
\hline Ethnic Group & 240 & \\
\hline Toffin & 156 & $65.00(58.92 ; 71.08)$ \\
\hline Others & 84 & $35.00(28.92 ; 41.08)$ \\
\hline Education level & 240 & \\
\hline Illiterate & 161 & $67.08(61.09 ; 73.07)$ \\
\hline Literate & 79 & $32.92(26.93 ; 38.90)$ \\
\hline Occupational status & 240 & \\
\hline Employed & 221 & $92.08(88.64 ; 95.52)$ \\
\hline Unemployed & 19 & $7.92(4.48 ; 11.36)$ \\
\hline Marital status & 240 & \\
\hline Cohabitation & 11 & $4.58(1.92 ; 7.25)$ \\
\hline Married (monogamy) & 159 & $66.25(60.22 ; 72.27)$ \\
\hline Married (polygamy) & 70 & $29.17(23.37 ; 34.96)$ \\
\hline Residence area & 240 & \\
\hline Lake area & 156 & $65.00(58.92 ; 71.08)$ \\
\hline Land area & 84 & $35.00(28.92 ; 41.08)$ \\
\hline Pre-pregnancy malaria & 227 & \\
\hline Yes & 10 & $4.41(1.72 ; 7.10)$ \\
\hline No & 217 & 95.59 (92.90; 98.28) \\
\hline
\end{tabular}

bio-efficacy and malaria infection in pre-pregnancy were significantly associated with the time to onset of the first malaria infection in the first trimester of pregnancy.

We also performed a Poisson model to study the effect of the three indicators of LLIN on the number of malaria infections occurring during the first trimester of pregnancy adjusted for the same covariates. In this analysis (Additional file 2: Table S2), the three indicators of the LLINs (the use, the physical integrity and the quantitative bio-efficacy) were significantly associated with the incidence of malaria infection during the first trimester of pregnancy, $($ IRRa $=0.40 ; \quad(0.20-0.78) ; \quad p<0.003 ; \quad$ IRRa $=0.44 ; \quad(0.24-$ $0.81) ; p<0.004 ;$ IRRa $=0.98 ;(0.95-0.99) ; p<0.02$ respectively), confirming the results of the Cox model.

\section{Discussion}

The peculiarity of our study was the ability to have followed the women from the pre-conceptional period until the end of the first trimester of pregnancy. This study identified two sets of essential results, i) the refined characterization of the protection given to the pregnant women by the LLIN against malaria infection during the first trimester of pregnancy and ii) new important elements in the reflection on the different indicators of LLIN's efficiency that characterize properly the real protection of pregnant women against malaria during this critical period.

We observed a general high possession and good use of LLIN by the study pregnant women. This is probably an indication of the success of the LLIN mass distribution campaigns carried out previously in Benin in 2011 and 2014. In all, the Cox model confirmed our working hypothesis that the different indicators were significantly related to the delay in malaria infection. Precisely, good 
Table 2 Indicators of possession, use, physical integrity and chemical efficacy of LLINs inspected during follow-up, Sô-Ava and Akassato, Benin 2015-2016 ( $N=240)$

\begin{tabular}{|c|c|c|c|c|c|c|}
\hline \multirow[t]{2}{*}{ Characteristics } & \multicolumn{2}{|c|}{ Pre-pregnancy } & \multicolumn{2}{|c|}{ Pregnancy visit 1} & \multicolumn{2}{|c|}{ Pregnancy visit 2} \\
\hline & Total & $\begin{array}{l}\text { Mean or proportion } \\
(95 \% \mathrm{Cl})\end{array}$ & Total & $\begin{array}{l}\text { Mean or proportion } \\
(95 \% \mathrm{Cl})\end{array}$ & Total & $\begin{array}{l}\text { Mean or proportion } \\
(95 \% \mathrm{Cl})\end{array}$ \\
\hline Possession of at least one LLIN/household & 240 & & 240 & & 203 & \\
\hline Yes & 237 & $98.75(96.17 ; 97.60)$ & 239 & $99.53(97.06 ; 99.94)$ & 202 & $99.51(96.53 ; 99.93)$ \\
\hline No & 3 & $1.25(0.40 ; 3.83)$ & 1 & $0.42(0.06 ; 2.94)$ & 1 & $0.49(0.07 ; 3.47)$ \\
\hline $\begin{array}{l}\text { Possession of LLIN according to WHO standards ( } 1 \\
\text { LLIN/2 people) }\end{array}$ & 237 & & 239 & & 202 & \\
\hline Yes & 178 & $75.11(69.16 ; 80.23)$ & 185 & $77.41(71.63 ; 82.30)$ & 164 & $81.19(75.14 ; 86.03)$ \\
\hline No & 59 & $24.89(19.77 ;$ 30.84) & 54 & $22.59(17.70 ; 28.37)$ & 38 & $18.81(13.96 ; 24.85)$ \\
\hline Use of LLIN by pregnant women & 237 & & 239 & & 202 & \\
\hline Yes & 199 & $83.97(78.69 ; 89.13)$ & 203 & 84.94 (79.78; 88.96) & 178 & $88.12(82.83 ; 91.93)$ \\
\hline No & 38 & $16.03(11.86 ; 21.31)$ & 36 & $15.06(11.04 ; 20.22)$ & 24 & $11.88(8.06 ; 17.17)$ \\
\hline Physical integrity of pregnant woman's LLIN & 237 & & 239 & & 202 & \\
\hline Good & 156 & $65.82(59.51 ; 71.62)$ & 145 & $60.67(54.29 ; 66.70)$ & 115 & $56.93(49.95 ; 63.64)$ \\
\hline Bad & 81 & $34.18(28.38 ; 40.49)$ & 94 & $39.33(33.30 ; 45.71)$ & 87 & $43.07(36.36 ; 50.05)$ \\
\hline Physical integrity of household's LLIN & 169 & & 195 & & 164 & \\
\hline Good & 101 & $59.76(52.12 ; 66.96)$ & 117 & $60.00(52.91 ; 66.70)$ & 96 & $58.54(50.77 ; 77.90)$ \\
\hline Bad & 68 & $40.24(33.04 ; 47.88)$ & 78 & $40.00(33.30 ; 47.09)$ & 68 & $41.46(34.10 ; 49.23)$ \\
\hline Bio-efficacy of pregnant women's LLIN & & & & & 198 & \\
\hline Yes & - & & - & & 12 & $6.06(3.46 ; 10.41)$ \\
\hline No & - & & - & & 186 & \\
\hline Bio-efficacy of household's LLIN & & & & & 126 & \\
\hline Yes & - & & - & & 7 & $5.56(2.64 ; 11.30)$ \\
\hline No & - & & - & & 119 & $94.44(88.70 ; 97.36)$ \\
\hline
\end{tabular}

use, good physical integrity and the quantitative bio-efficacy of the LLIN were found to be associated with a later occurrence of the first malarial infection during the first trimester of pregnancy. In this model the physical integrity of the LLIN was associated only marginally significantly with the delay of the first malaria infection but showed significant associations in the Poisson regression model. Five pregnant women had malaria infection twice in our study. Two studies did not find any association between LLIN usage by pregnant women and the risk of malaria infection [21, 22]. Since the effectiveness of LLIN to reduce the malaria burden has been extensively established [23] including in pregnant women $[15,24-28]$, those result show probably the limit of the two classical indicators of ownership and reported LLIN use the previous night to characterize adequately the optimal protection of the pregnant woman against the occurrence of a malaria infection. All these elements point out the need to consider, in addition to the classical ownership and reported use indicators, the physical integrity and bio-efficacy indicators should be taken into account in evaluation studies of LLIN efficiency to reduce the malaria burden in pregnant women.

In our study, the high proportions of good use and LLINs with good physical integrity are in favor of a good physical barrier conferred by LLIN to the pregnant women during the first trimester of pregnancy. Nevertheless, a more worrying result was the small minority of

Table 3 Proportion of pregnant women infected during the first trimester of pregnancy, Sô-Ava and Akassato, Benin 2015-2016

\begin{tabular}{|c|c|c|c|c|c|c|c|c|}
\hline \multirow{2}{*}{$\begin{array}{l}\text { Malaria } \\
\text { infection }\end{array}$} & \multicolumn{2}{|c|}{ Pre-pregnancy visit } & \multicolumn{2}{|c|}{ Visit 1} & \multicolumn{2}{|c|}{ Visit 2} & \multicolumn{2}{|c|}{ Visit 3} \\
\hline & $n$ & $\%(95 \% \mathrm{Cl})$ & $n$ & $\%(95 \%$ Cl) & $n$ & $\%(95 \%$ Cl) & $n$ & $\%(95 \% \mathrm{Cl})$ \\
\hline Total & 227 & & 234 & & 199 & & 180 & \\
\hline Yes & 10 & $4.41(2.37 ; 8.03)$ & 14 & $5.98(3.56 ; 9.88)$ & 10 & $5.02(2.71 ; 9.13)$ & 17 & $9.44(5.92 ; 14.73)$ \\
\hline
\end{tabular}

A total of 239 pregnant women were followed during 626.63 person-months, with a median follow-up time of 88 days (Interquartile interval: $65-95$ ) 


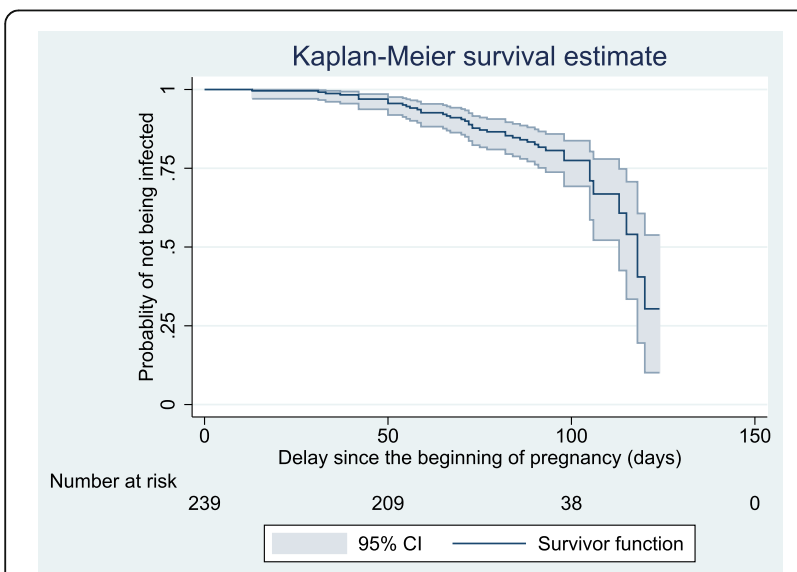

Fig. 2 Probability of non-occurrence of malaria infection in women during the first trimester of pregnancy, Sô-ava and Akassato, Benin, 2015-2016

LLIN reaching the bio-efficacy threshold set by the WHO recommendations. This raises the highly important question of the duration of the LLINs bio-efficacy in field conditions. Given that optimal protection by the LLIN is provided by the combination of its physical barrier and chemical efficacy, we can conclude that the extreme majority of women in the study were not optimally protected against malaria in the first trimester of their pregnancy by the LLIN they used. This important conclusion would have been missed if only based on the ownership and usage classical indicators.

Table 4 Factors associated with the time to onset of the first malaria infection during the first trimester of pregnancy (multivariate Cox model, N=190 pregnant women); Sô-Ava and Akassato, Benin 2015-2016

\begin{tabular}{llllll}
\hline Variables (terms) & \multicolumn{3}{c}{ Multivariatble Cox model } \\
\cline { 2 - 5 } & $\mathrm{N}$ & HRa & Cl 95\% & pvalue \\
\hline $\begin{array}{l}\text { Use of LLIN by the woman } \\
\text { the week before the visit }\end{array}$ & 190 & & & \\
& No & 36 & 1 & & \\
Yes & 154 & 0.38 & $(0.18-0.80)$ & $<0.001$
\end{tabular}

Physical integrity of the pregnant 190 woman's LLIN

$$
\begin{array}{llllll}
\text { Bad } & 78 & 1 & & \\
\text { Good } & 112 & 0.59 & (0.29-1.19) & 0.07 \\
& 190 & 0.97 & (0.94-1.00) & 0.04 \\
& & & & \\
& 190 & & & \\
\text { Yes } & 9 & 1 & & \\
\text { No } & 181 & 0.27 & (0.09-0.74) & 0.01
\end{array}
$$

Quantitative bio-efficacy ${ }^{\mathrm{a}}$ of the pregnant woman's LLIN Malaria before pregnancy

$N$ Total, HRa Hazard ratio adjusted, CI 95\% Confidence Interval at 95\%, LLIN Long Lasting Impregnated bedNets, pvalue one-sided pvalue ${ }^{a}$ Quantitative bio-efficacy is defined as the proportion of female anopheles who died $24 \mathrm{~h}$ after exposure to the LLIN
A strength of our study is that for the first time in a malaria cohort, the women were seen at a pre-conceptional stage which allowed to follow them on the very beginning of their pregnancy. This is an important strenght compared to non preconcepional studies. Although our results indicate minimal selection bias, the moderate size of our sample and the particular facies of the study area (lake zone) impose some caution on the representativeness of the results.

\section{Conclusion}

Our study demonstrated for the first time an overall good physical protection against the malaria vector conferred by LLIN in pregnant women in their first trimester of pregnancy, but low chemical protection in our study area. An important conclusion is that, in addition to the traditional indicator of possession of LLINs by pregnant women, it is essential to take into account other indicators such as actual use, physical integrity and bio-efficiency of LLIN, since all these indicators reflect independently from each other the real protection against malaria of this population. Further studies are then needed to assess the generalizability of our results and also to control the duration of the chemical effectiveness of the LLIN distributed on the territory.

\section{Additional files}

Additional file 1: Table S1. Factors associated with delay in the first malaria infection during the first trimester of pregnancy, univariate Cox analysis ( $N=240)$; Sô-ava and Akassato, Benin 2015-2016. (DOCX 23 kb)

Additional file 2: Table S2. Factors associated with the number of malaria infections during the first trimester of pregnancy (multivariate Poisson regression model, $N=194$ pregnant women); Sô-ava and Akassato, Benin 2015-2016. (DOCX 16 kb)

\section{Abbreviations}

ACT: Artemisinin Combined Therapy; CER-ISBA: Ethics Committee of the Institute of Applied Biomedical Sciences; HRa: Hazard Ratio adjusted; IPTp: Intermittent Preventive Treatment in Pregnant women; IRRa: Incidence Rate Ratio adjusted; LBW: Low Birth Weight; LLIN: Long Lasting Insecticidal Nets; RDT: Rapid Diagnostic Tests; SP: Sulfadoxine - Pyrimethamine; TBS: Thick Blood Smear; WHO: World Health Organization

\section{Acknowledgements}

We acknowledge all the pregnant women, health center and field workers and the local authorities of Sô-Ava and Akassato Districts who participated in the EVALMOUS study.

\section{Funding}

This work was supported by "Expertise France -Initiative 5\%" (Mission $n^{\circ}$ 15SANIN110), "Fondation Simone Beer" under the aegis of "Fondation de France" and the French "Agence Nationale de la Recherche" (ANR-13JSV1-004-01).

\section{Availability of data and materials}

The datasets used and/or analysed during the current study are available from the corresponding author on reasonable request.

\section{Authors' contributions}

Project management: $C H, A D, V B$ and GC (Principal Investigator). Field, Epidemiology and data collection: $\mathrm{CH}, \mathrm{AD}, \mathrm{MA}, \mathrm{EY}$ and GC. Biology and 
molecular analyses: NF LLIN's laboratory tests: AB, CS and AD. Mapping: SE, $\mathrm{CH}$ and GC. Statistical analysis: $\mathrm{CH}, \mathrm{AD}, \mathrm{PH}$ and GC. Manuscript writing: $\mathrm{CH}$, $A D, S E, P H, A B, C S, N F, M A, E Y, V B$ and GC. All authors read and approved the final manuscript.

\section{Ethics approval and consent to participate}

The RECIPAL and EVALMOUS studies have received the ethical approval from the Ethics Committee of the Institute of Applied Biomedical Sciences (CERISBA: $n^{\circ} 60$ of the 06/01/2015) and the Ministry of Health in Benin as well as from the Comité Consultatif de Déontologie et d'Ethique (CCDE) from IRD in France. Before any inclusion in the study, free and informed consent was obtained from each woman after the study had been presented to her in the local language.

\section{Consent for publication}

Not Applicable.

\section{Competing interests}

The authors declare that they have no competing interests.

\section{Publisher's Note}

Springer Nature remains neutral with regard to jurisdictional claims in published maps and institutional affiliations.

\section{Author details}

'UMR216-MERIT, French National Research Institute for Sustainable Development (IRD), Université Paris Descartes, 75006 Paris, France. ${ }^{2}$ Centre d'Etude et de Recherche sur le Paludisme Associé à la Grossesse et à l'Enfance (CERPAGE), Faculté des Sciences de la Santé, Cotonou, Bénin. ${ }^{3}$ Faculté des Sciences et Techniques, Université d'Abomey-Calavi, Cotonou, Bénin. ${ }^{4}$ Centre de Recherche Entomologique de Cotonou, Cotonou, Benin. ${ }^{5}$ University of Ibadan, Ibadan, Nigeria.

\section{Received: 10 January 2018 Accepted: 23 May 2018}

\section{Published online: 01 June 2018}

\section{References}

1. Schantz-Dunn J, Nour NM. Malaria and Pregnancy: a Global Health perspective. Rev Obstet Gynecol. 2009;2(3):186-92.

2. Ayoola OO, Whatmore A, Balogun WO, Jarrett OO, Cruickshank JK, Clayton PE. Maternal malaria status and metabolic profiles in pregnancy and in cord blood: relationships with birth size in Nigerian infants. Malar J. 2012;11:75.

3. Menéndez C, Romagosa C, Ismail MR, Carrilho C, Saute F, Osman N, et al. An Autopsy Study of Maternal Mortality in Mozambique: The Contribution of Infectious Diseases. Wright L, editor. PLoS Med. 2008:5(2):e44

4. Guyatt HL, Snow RW. The epidemiology and burden of plasmodium falciparum-related anemia among pregnant women in sub-Saharan Africa. Am J Trop Med Hyg. 2001;64(1 suppl):36-44.

5. WHO | Malaria in pregnant women. Available from: http://www.who.int/ malaria/areas/high_risk_groups/pregnancy/en/. Accessed 17 Aug 2017.

6. WHO-HTM-GMP-2017.4-fre.pdf. Available from: http://apps.who.int/iris/bitstream/ 10665/254913/1/WHO-HTM-GMP-2017.4-fre.pdf?ua=1. Accessed 28 Apr 2017.

7. Briand V, Cottrell G, Massougbodji A, Cot M. Intermittent preventive treatment for the prevention of malaria during pregnancy in high transmission areas. Malar J. 2007;6(1):160.

8. Shulman CE, Dorman EK, Cutts F, Kawuondo K, Bulmer JN, Peshu N, et al. Intermittent sulphadoxine-pyrimethamine to prevent severe anaemia secondary to malaria in pregnancy: a randomised placebo-controlled trial. Lancet Lond Engl. 1999;353(9153):632-6.

9. Njagi JK, Magnussen P, Estambale B, Ouma J, Mugo B. Prevention of anaemia in pregnancy using insecticide-treated bednets and sulfadoxinepyrimethamine in a highly malarious area of Kenya: a randomized controlled trial. Trans R Soc Trop Med Hyg. 2003:97(3):277-82.

10. Schultz LJ, Steketee RW, Macheso A, Kazembe P, Chitsulo L, Wirima JJ. The efficacy of antimalarial regimens containing Sulfadoxine-Pyrimethamine and/or chloroquine in preventing peripheral and placental plasmodium falciparum infection among pregnant women in Malawi. Am J Trop Med Hyg. 1994;51(5):515-22.

11. Valea I, Tinto H, Drabo MK, Huybregts L, Sorgho H, Ouedraogo J-B, et al. An analysis of timing and frequency of malaria infection during pregnancy in relation to the risk of low birth weight, anaemia and perinatal mortality in Burkina Faso. Malar J. 2012:11:71.

12. Huynh B-T, Fievet N, Gbaguidi G, Dechavanne S, Borgella S, Guézo-Mévo B, et al. Influence of the timing of malaria infection during pregnancy on birth weight and on maternal anemia in Benin. Am J Trop Med Hyg. 2011;85(2): 214-20.

13. Cottrell G, Mary J-Y, Barro D, Cot M. The importance of the period of malarial infection during pregnancy on birth weight in tropical africa. Am J Trop Med Hyg. 2007;76(5):849-54.

14. Ouédraogo S, Koura GK, Accrombessi MM, Bodeau-Livinec F, Massougbodji A, Cot M. Maternal anemia at first antenatal visit: prevalence and risk factors in a malaria-endemic area in Benin. Am J Trop Med Hyg. 2012;87(3):418-24.

15. Gamble C, Ekwaru PJ, Garner P, ter Kuile FO. Insecticide-treated nets for the prevention of malaria in pregnancy: a systematic review of randomised controlled trials. PLoS Med. 2007:4(3):e107.

16. Bennett A, Smith SJ, Yambasu S, Jambai A, Alemu W, Kabano A, et al. Household possession and use of insecticide-treated mosquito nets in Sierra Leone 6 months after a national mass-distribution campaign. PLoS One. 2012;7(5):e37927.

17. Accrombessi M, Yovo E, Cottrell G, Agbota G, Gartner A, Martin-Prevel Y, et al. Cohort profile: effect of malaria in early pregnancy on fetal growth in Benin (RECIPAL preconceptional cohort). BMJ Open. 2018;8(1):8.

18. Planche T, Krishna S, Kombila M, Engel K, Faucher JF, Ngou-Milama E, et al. Comparison of methods for the rapid laboratory assessment of children with malaria. Am J Trop Med Hyg. 2001;65(5):599-602.

19. WHO Guidance for MIP Prevention and Treatment.pdf. Available from: http://www.mchip.net/sites/default/files/03.\%20\%20WHO\%20Guidance\%20 for\%20MIP\%20Prevention\%20and\%20Treatment.pdf. Accessed 19 Jan 2017.

20. World Health Organization, others. Guidelines for monitoring the durability of long-lasting insecticidal mosquito nets under operational conditions. Guidel Monit Durab Long-Lasting Insecticidal Mosq Nets Oper Cond. 2011. Available from: http://apps.who.int/iris/handle/10665/44610. Accessed 9 May 2017.

21. Famanta A, Diakite M, Diawara SI, Diakité SA, Doumbia S, Traoré K, et al. Prévalence du paludisme maternel, placentaire et du petit poids de naissance au cours du travail d'accouchement et en post-partum en milieu périurbain à Bamako (Mali). Santé. 2011;21(1):3-7.

22. Ouattara AF, Dagnogo M, Olliaro PL, Raso G, Tanner M, Utzinger J, et al. Plasmodium falciparum infection and clinical indicators in relation to net coverage in central Côte d'Ivoire. Parasit Vectors. 2014;7(1):306.

23. Bhatt S, Weiss DJ, Cameron E, Bisanzio D, Mappin B, Dalrymple U, et al. The effect of malaria control on plasmodium falciparum in Africa between 2000 and 2015. Nature. 2015;526(7572):207-11.

24. Shulman CE, Dorman EK, Talisuna AO, Lowe BS, Nevill C, Snow RW, et al. A community randomized controlled trial of insecticide-treated bednets for the prevention of malaria and anaemia among primigravid women on the Kenyan coast. Tropical Med Int Health. 1998;3(3):197-204.

25. Lengeler $C$. Insecticide-treated bed nets and curtains for preventing malaria. Cochrane Database Syst Rev. 2004;2:CD000363.

26. Ter Kuile FO, Terlouw DJ, Phillips-Howard PA, Hawley WA, Friedman JF, Kariuki SK, et al. Reduction of malaria during pregnancy by permethrintreated bed nets in an area of intense perennial malaria transmission in western Kenya. Am J Trop Med Hyg. 2003;68:50-60.

27. Browne EN, Maude GH, Binka FN. The impact of insecticide-treated bednets on malaria and anaemia in pregnancy in Kassena-Nankana district, Ghana: a randomized controlled trial. Trop Med Int Health TM IH. 2001;6(9):667-76.

28. Kayentao K, Garner P, van Eijk AM, Naidoo I, Roper C, Mulokozi A, et al. Intermittent preventive therapy for malaria during pregnancy using 2 vs 3 or more doses of sulfadoxine-pyrimethamine and risk of low birth weight in Africa: systematic review and meta-analysis. JAMA. 2013:309(6):594-604. 